\title{
Práticas integrativas \\ e complementares em saúde, \\ uma nova eficácia para o SUS
}

EMÍLIO TELESI JÚNIOR ${ }^{I}$

\section{Introdução}

A S PRÁTICAS integrativas de saúde paulatinamente se tornaram uma realidade na rede de atenção à saúde pública em São Paulo. Se no início dos anos 2000 havia cerca de seis unidades da Secretaria Municipal da Saúde de São Paulo que adotavam as Práticas Integrativas e Complementares em saúde (PICS), a partir de 2002, com o uso continuado de novos referenciais de educação, a SMS-SP deu início ao processo de expansão maciça dessas modalidades em toda a rede de saúde. É um prazer constatar que atualmente mais de 520 unidades de saúde praticam pelo menos uma das distintas modalidades que integram o rol dessas práticas, como as medicina tradicional chinesa, a homeopatia, a medicina antroposófica, além de recursos terapêuticos como a fitoterapia, as práticas corporais e meditativas. ${ }^{1}$

Esse avanço pode ser entendido como expressão de um movimento que se identifica com novos modos de aprender e praticar a saúde, já que essas práticas caracterizam-se pela interdisciplinaridade e por linguagens singulares, próprias, que em geral se contrapõem à visão altamente tecnológica de saúde que impera na sociedade de mercado, dominada por convênios de saúde cujo objetivo precípuo é gerar lucro e fragmentar o tratamento do paciente em especialidades que não dão conta da totalidade do ser humano em busca de remédio para seus males.

O crescimento da população, o aumento da expectativa de vida, a multiplicação de técnicas, disciplinas e novas especialidades médicas que proliferam de modo alucinante são ao mesmo tempo a riqueza e o drama maior do setor saúde, especialmente por afetarem as relações comunicativas, a ação coordenada dos novos conhecimentos e a integração do conjunto imenso de informações que se produz. Quando se leva em conta a necessidade de tomar decisões complexas, a integração entre as distintas disciplinas é o desafio mais premente da saúde, que é obrigada a enfrentar a diversidade e a multiplicidade de formação dos profissionais para conceber projetos de trabalho integrados, que contribuam para o intercâmbio de informações tão diversificadas, de modo a dar sentido às intervenções sobre a saúde e seus sucedâneos. Atualmente muitos pesquisadores vêm corroborando essa visão, e entre tantos outros, pode-se mencionar Patrik 
Paul (2013), que, ao enfatizar a importância da subjetividade nas práticas e nos cuidados médicos, afirma ser a pluralidade disciplinar o caminho para uma visão mais ampla e global do ser humano.

É nesse panorama que o repertório de práticas integrativas, com seu vasto arsenal de recursos, pode contribuir para a integração disciplinar, pois descende de uma tradição milenar de uso continuado e praticamente inalterado dos mesmos recursos tecnológicos, pautados por natureza interdisciplinar. A importância dessa característica permite afirmar que se trata de algo absolutamente sustentável e de extrema importância para as práticas que se valorizam no trabalho de saúde pública.

O uso dessas "práticas integrativas e complementares" no Sistema Único de Saúde merece reflexão, especialmente quando se investiga o sentido de sua adoção na política nacional de um país como o Brasil, uma sociedade complexa que tem incorporado recursos tecnológicos cada vez mais sofisticados e dispendiosos. Nesse contexto, o que justifica a luta pela implementação e expansão das práticas integrativas? Talvez a melhor resposta venha dos trabalhadores de saúde engajados na prática das PICS. Tentar perceber o sentido dessas práticas no dia a dia de trabalho, vivendo-as e utilizando-as, sem dúvida é a melhor forma de avaliar sua importância para a saúde coletiva. Pois aqueles que as praticam o fazem não simplesmente porque aprenderam outra técnica de saúde e desejam aplicá-la, mas movidos pela vontade de afirmar uma identidade de cuidado oposta ao modelo dominante. Trata-se de mostrar que existem práticas alternativas capazes de fazer a diferença e se tornar parte de um processo renovado de implementação de modos alternativos de promover saúde, não lucrativos, menos onerosos e mais aptos a cuidar do ser humano em sua totalidade.

\section{As práticas integrativas e complementares nos sistemas de saúde}

A origem das práticas integrativas nos sistemas públicos de saúde vem de longa data. No final dos anos 1970, com a Primeira Conferência Internacional de Assistência Primária em Saúde (Alma Ata, Rússia, 1978), as primeiras recomendações para a implantação das medicinas tradicionais e práticas complementares difundiram-se em todo o mundo. No Brasil esse movimento ganhou força a partir da Oitava Conferência Nacional de Saúde (1986), e desde então somente se expandiu.

A partir de Alma Ata a Organização Mundial de Saúde criou o Programa de Medicina Tradicional, objetivando a formulação de políticas em defesa dos conhecimentos tradicionais em saúde. Em vários de seus comunicados e resoluções, a OMS firmou o compromisso de incentivar os Estados-membro a formularem políticas públicas para uso racional e integrado das Medicinas Tradicionais e das Medicinas Complementares e Alternativas nos sistemas nacionais de atenção à saúde, bem como para o desenvolvimento de estudos científicos para melhor conhecimento de sua segurança, eficácia e qualidade. 
Tais sistemas e recursos envolvem abordagens que buscam estimular os mecanismos naturais de prevenção de agravos e recuperação da saúde por meio de tecnologias eficazes e seguras, com ênfase na escuta acolhedora, no desenvolvimento do vínculo terapêutico e na integração do ser humano com o meio ambiente e a sociedade. Outros pontos compartilhados pelas diversas práticas abrangidas nesse campo são a visão ampliada do processo saúde-doença e a promoção global do cuidado humano, especialmente do autocuidado.

O documento "Estratégia da OMS sobre Medicina Tradicional 20022005 " reafirma os princípios de Alma Ata. ${ }^{2}$ E destaca a organização dessas práticas em nosso país:

No Brasil, a legitimação e a institucionalização dessas abordagens de atenção à saúde iniciaram-se a partir da década de 80 , principalmente, após a criação do SUS. Com a descentralização e a participação popular, os estados e municípios ganharam maior autonomia na definição de suas políticas e ações em saúde, vindo a implantar as experiências pioneiras. (ibidem)

A partir da Oitava Conferência Nacional de Saúde, por meio de Relatórios e Portarias, diversos documentos e eventos nacionais passaram a fazer parte da trajetória de implantação das práticas integrativas, destacando-se o esforço de regularizar a homeopatia, a acupuntura, o uso de plantas medicinais, a fitoterapia, a adoção de práticas corporais e meditativas, entre outras, viabilizadas pela criação de convênios e por diversos grupos de trabalho dedicados a elaborar projetos e políticas para a área.

Coerente com as necessidades e as demandas em sua área de abrangência, a Atenção Básica da Secretaria Municipal da Saúde de São Paulo, a partir de 2002, procurou fortalecer as ações de promoção da saúde ainda não praticadas nesse setor, de modo a enriquecer o arsenal de recursos já existentes e ampliar o campo de ação para incluir outros modos terapêuticos de atuação em benefício das políticas públicas e da comunidade. Desde então, a oferta das práticas integrativas e complementares vem aumentando e contribuindo para ampliar a integralidade da assistência, de forma humanizada e acolhedora.

Os principais objetivos que, a partir de 2002, nortearam o movimento de expansão das Práticas na SMS do município de São Paulo foram os seguintes:

1 - Desenvolver e consolidar as Práticas Integrativas e Complementares nas Unidades e Serviços da Secretaria Municipal da Saúde, na perspectiva da prevenção de agravos e da promoção e recuperação da saúde, com ênfase na Assistência Primária em Saúde, voltada para o cuidado continuado de forma integral e interdisciplinar.

2 - Contribuir para aumentar a resolubilidade da rede assistencial da SMS-SP, com o uso de técnicas simples, de baixo custo, artesanais, sustentáveis e comprovadamente eficazes.

3 - Desenvolver ações planejadas com as demais áreas e redes assistenciais da SMS-SP, com outras secretarias municipais e com setores sociais interessados na promoção da saúde. 
Deve-se ressaltar que essa inovação tecnológica não é privilégio apenas da cidade de São Paulo, uma vez que muitos estados e municípios brasileiros vêm incorporando essas modalidades de atenção e renovação do cuidado na saúde. É importante sublinar, também, que a expressão "cuidado na saúde" vem merecendo estudos e reflexões por parte de diversos acadêmicos de grande importância na área, como é o caso do estudo de J. R. C. M. Ayres (2005) sobre a reconstrução das práticas de saúde.

\section{Duas racionalidades médicas: a oriental e a ocidental}

Quando nos perguntamos de onde vieram as sementes do pensamento moderno ocidental não hesitamos em concordar com Gleiser (1997) quando afirma que tiveram origem na Grécia Antiga, em particular no período compreendido entre os séculos IV e VI a. C. O início dessa aventura intelectual é definido pelo aparecimento dos filósofos pré-socráticos que, segundo o estudioso, foram os primeiros pensadores a tentar responder questões sobre a natureza usando a razão e não a mitologia ou a religião.

O interesse pelo saber racional, instigado pelo mistério que sempre motivou o pensamento religioso está na raiz de toda ciência. Segundo Aristóteles, Tales foi o primeiro filósofo a postular que a substância fundamental do Cosmo seria a água, o que revela uma visão profundamente orgânica da natureza. Foi também com Tales de Mileto que nasceu, no mundo ocidental, a ideia de buscar uma estrutura material unificada do Universo, algo que ainda motiva boa parcela do trabalho de cientistas de todas as partes do planeta, da física de partículas elementares à biologia molecular e genética.

De acordo com Tales e seus discípulos, a natureza é uma entidade dinâmica, em constante transformação, que se renova indefinidamente em formas e criações (ibidem). Essa visão foi criticada por outra escola pré-socrática, a de Parmênides, que defendia ideias opostas às de Tales, afirmando que o essencial nunca pode se transformar. O que "é" simplesmente é. Talvez se possa identificar nessa ideia o germe da concepção de uma entidade eterna, transcendente, que está além das transformações, e que considera a mudança menos fundamental que a essência primeira. A partir dessa constatação, é possível afirmar que o debate entre o eterno e o novo, o Ser e o Vir-a-Ser, já havia começado no Ocidente há cerca de 2.500 anos.

Mas é preciso recuar mais tempo quando se levam em conta os pensadores e os filósofos do mundo oriental. Uma grande quantidade de textos cosmológicos legados ao taoísmo informa-nos sobre um Sopro primordial, denominado Qi (ou $C h \hat{1})$, preexistente à formação do Céu e da Terra. O Tao Te King, organizado por Lao Tsé (s. d.), é considerado o mais importante livro a respeito do Taoísmo. Em seu capítulo 42 diz o seguinte:

O Tao gera o Um

O Um gera o Dois 
O Dois gera o Três

O Três gera todas as coisas

Todas as coisas dão as costas ao escuro,

Dirigindo-se para a luz.

A energia que entre eles flui lhes fornece a harmonia.

Enquanto o pensamento ocidental foi a base da chamada medicina científica moderna, a essência da filosofia oriental foi o alicerce das chamadas medicinas tradicionais orientais, em especial a chinesa. No entanto, recentemente, vimos observando que a tendência da medicina ocidental é incluir em seu "arsenal terapêutico" procedimentos oriundos das medicinas tradicionais, especialmente aquelas praticadas no Oriente, como a acupuntura, o moxabustão, a prática da meditação, o tai-chi, as artes marciais, a fitoterapia, a dietoterapia, entre outras modalidades terapêuticas (Portaria 971 - PNPIC). A esse respeito, é preciso reconhecer o enorme esforço de pesquisadores do país em comprovar cientificamente os conhecimentos milenares, no sentido de legitimá-los e inscrevê-los no campo das especialidades médicas ocidentais. ${ }^{3}$

Apesar de trabalharem com paradigmas médicos distintos, orientados por cosmologias conflitantes, as racionalidades médicas oriental e científica têm alguns pontos de confluência. Percebe-se que tanto a medicina ocidental quanto a oriental compartilham o mesmo objeto, o ser humano doente, além de visarem ao mesmo objetivo de cura do indivíduo, restabelecendo-lhe a saúde, ou, até mesmo, buscando expandi-la. Além disso, baseiam-se na mesma cosmologia integradora da natureza e do ser humano e, em relação à intimidade humana, defendem o equilíbrio fisiológico, psicológico e postural. O meio ambiente, natural e social, bem como as circunstâncias do processo de adoecimento têm, para ambas, grande importância no estabelecimento de diagnósticos.

No que diz respeito à concepção do termo saúde, para as duas racionalidades médicas a saúde não constitui uma ciência em si ou mesmo um campo separado de outras instâncias da realidade social. Por isso, tanto no que concerne à problemática teórica quanto à metodológica, a promoção e o restabelecimento da saúde estão submetidos a mesmas vicissitudes, avanços, recuos, interrogações e perspectivas integradoras, seja da óptica ocidental, seja da oriental (Apezechea, 1984). A partir das semelhanças apontadas, pode-se concluir que a especificidade do setor saúde é dada por inflexões socioeconômicas, políticas e ideológicas relacionadas ao saber teórico e prático sobre saúde e doença, além de recair sobre a institucionalização, a organização, a administração e a avaliação dos serviços e, especialmente, sobre a clientela dos Sistemas de Saúde. Nesse caráter peculiar e diferencial reside sua abrangência multidisciplinar e estratégica. O reconhecimento da realidade complexa que diz respeito ao campo da saúde demanda conhecimentos distintos, integrados e interdisciplinares, e coloca de forma imediata o problema da intervenção, seja sobre o indivíduo, seja sobre a coletividade. É nesse sentido que a saúde requer uma abordagem dialética, que 
compreende para transformar, e cuja teoria é permanentemente desafiada pela prática, e surge a partir dela. Para ampliar essa compreensão sobre o campo da saúde e suas complexas relações recomendamos a leitura de Minayo (1995).

$\mathrm{Na}$ história das medicinas ocidental e oriental as questões relativas à compreensão do ser humano também apresentam analogias. Para ambas, é evidente que o homem não pode ser resumido a certo número de recortes orgânicos, por exemplo. Não é suficiente adicionar determinada quantidade de órgãos para criar uma vida. As noções de integralidade e complexidade estão no cerne das discussões da área médica e devem nos interrogar permanentemente. Com efeito, a perda da abordagem do ser humano enquanto globalidade em benefício de um olhar técnico e único, próprio da medicina ocidental, cria mal estar no sujeito doente, que se sente despossuído de seu estatuto de sujeito. A abordagem da medicina oriental, ao contrário, busca justamente preservar a globalidade do sujeito, e o processo vital e social em geral. Procura a causalidade da doença dentro de um contexto mais amplo, multifatorial, e é contrária à hiperespecialização. Resta-nos investigar os modos de articular e integrar os dois saberes.

Não é difícil constatar que a medicina científica moderna trabalha essencialmente com a doença. Na verdade, o conceito de fisiopatologia permite um distanciamento entre o sujeito e sua saúde/doença. A afirmação corriqueira da Clínica de que "não existem doenças e sim doentes" é desmentida pela insistência em uma prática fragmentada e instrumentalista, que cumpre a função de assinalar e reforçar a distância entre o sujeito integral e a especificidade de sua doença. Nesse sentido, é inegável que o objeto da fisiopatologia, hegemônico na formulação da Clínica Médica, é a doença e não o doente. Já para o campo das práticas de Saúde Pública nunca será possível um recorte desse tipo. Ao contrário, cabe à Saúde Pública lidar com o doente, mas sempre no plural, restaurando a cada passo o caráter social de seu objeto fundamental, o coletivo população.

\section{Relações comunicativas entre as medicinas oriental e ocidental}

A dimensão integradora do homem e da natureza numa perspectiva de macro e microuniversos, que postula a integralidade do sujeito humano, constituída de aspectos psicobiológicos, sociais e espirituais, embasa as dimensões das racionalidades médicas oriental e ocidental. No entanto, há diferenças no que concerne aos aspectos relativos à presença ou não de elementos cosmológicos, e especialmente quanto ao diagnóstico e ao modelo terapêutico.

Os diferentes fenômenos que levaram a modificações sucessivas da visão da medicina científica moderna não atingiram as medicinas tradicionais nascidas no Oriente. Para essas medicinas, os elementos cosmológicos desempenham um papel importante na determinação das constituições individuais, enquanto para a racionalidade médica ocidental o elemento cosmológico é desconsiderado, já que desprovido de base científica. Portanto, não tem valor algum. E não constitui objeto de investigação da ciência médica, na medida em que o objeto epistemológico desse sistema é a doença, sua identificação, etiologia e classifica- 
ção macro ou microanatômica. Ou seja, somente o que pode ser visto, sentido e medido matematicamente pelo homem é considerado pela medicina ocidental.

No entendimento de Luz (1993), a medicina moderna desde seu início, com a criação das escolas médicas, procurou afastar-se da explicação mítica para os problemas de saúde. A visão de Deus, dos espíritos e toda doutrina ligada aos ensinamentos judaicos e cristãos foram afastados da ciência médica moderna (Luz, 1993). Na perspectiva das medicinas orientais, ao contrário, toda doença é decorrente de um desequilíbrio em que interagem forças naturais (materiais) e cosmológicas (imateriais). Esse desequilíbrio é visto como uma ruptura de harmonia biológica, social e cósmica, e inclui o ser humano ao mesmo tempo enquanto expressão e partícipe. De acordo com as medicinas orientais, absurdo seria não considerar a harmonia e a relação entre os elementos do micro e do macrocosmos. A partir desse prisma, é possível entender por que Padilla Corral (2006) considera a Medicina Tradicional Oriental, em sua origem, não uma medicina em sentido estrito, já que não tem a intenção de tratar as doenças, mas um aprendizado de como viver a vida. Segundo o autor, à medida que nos aproximamos da época moderna surge um outro modo de tratar as doenças, pois "o homem adoece ou é propenso a adoecer porque não sabe viver e desfrutar a vida, porque perdeu essa conexão, esse intercâmbio com seu Universo. Essa falta de conexão e interrelação com o meio é o que o faz enfermar, é o que hoje em dia se chama entorno: a relação com meu universo, a relação comigo mesmo, a relação com os demais" (ibidem).

Diante do exposto, é possível concluir que trabalhamos com o pressuposto da existência de duas racionalidades distintas para explicar a realidade de saúde e intervir sobre ela: a que se assenta sobre a ciência médica moderna, de caráter hegemônico em nossa sociedade, e a que se apresenta como medicina tradicional, ligada à tradição oriental, e que vem sendo considerada válida pelo sistema oficial de saúde pública. Pode-se dizer que os conceitos das medicinas tradicionais integram, cada vez com maior assiduidade, as práticas sociais em curso, participando ativamente da realidade social brasileira. Portanto, hoje as medicinas tradicionais são parte integrante do conjunto de forças vivas presentes nos sistemas de saúde.

\section{Rompendo as barreiras}

O diálogo entre as duas racionalidades médicas já existe entre nós. Percebe-se que o avanço das medicinas tradicionais nos países ocidentais tem criado condições para favorecer a troca entre as duas correntes de pensamento. É interessante realçar que uma das práticas que caracterizam a complexidade dos problemas sociais, em especial no campo da saúde pública, é o enfoque interdisciplinar das pesquisas científicas e tecnológicas. Pode-se constatar que a pesquisa de caráter interdisciplinar vem ganhando espaço no campo da saúde pública. Nos anos recentes, todas as áreas da saúde têm merecido estudos transversais que aliam diversas especialidades, empenhadas na busca continuada de transfe- 
rência de tecnologias e de incremento do processo educativo visando à aquisição de novos hábitos por parte da população. O objetivo é alcançar um mínimo de soluções para as contradições que estruturam e garantem a complexidade investigada. O processo pode levar a uma "medicina plural", mais apta a responder aos desafios da complexidade e à riqueza antropológica da medicina, a despeito de nossas próprias representações, que ainda resistem como forma de obstáculos à comunicação entre as duas racionalidades.

O encontro e a comunicação entre as duas correntes de pensamento médico, promovidos no campo da saúde pública, poderiam constituir um sólido alicerce antropológico, fundamental para manter a continuidade da tensão criativa entre essas diferentes bases filosóficas. A busca de relações entre elas sem dúvida contribui para a construção de um novo modelo de representação das ações no campo da saúde, mais apto a enfrentar os desafios ligados à complexidade da vida moderna. Diante desse deslocamento de olhares da ciência, precisamos de conhecimentos que revelem as ligações, as articulações, a solidariedade, as interdependências, as implicações e as complexidades de nosso objeto de estudo, de modo a podermos contribuir para a aproximação entre a visão holística das medicinas tradicionais e o dualismo cartesiano que está na raiz do pensamento e da ciência moderna. Embora os paradigmas constitutivos das duas práticas médicas sejam diferentes e contraditórios, pois enquanto um enfoca a doença o outro prioriza a saúde, a comunicação entre eles pode renovar as intervenções na saúde pública, que tem se esforçado por garantir seu diálogo.

É preciso garantir a posição da saúde pública como um lugar de debate de ideias. Sem dúvida, ela ainda preserva um espaço onde se pode pensar a saúde, espaço permanentemente aberto para refletir sobre a transformação das práticas, para que tenhamos mais comprometimento com as necessidades de saúde da população. Nesse sentido, as Práticas Integrativas e Complementares em saúde funcionam como uma das respostas a esse debate de ideias, na medida em que fomentam práticas estratégicas e pensamentos renovados sobre a saúde pública. Renovados porque reivindicam a diversidade interdisciplinar. Pois para as Práticas não há fronteiras e nem interdições entre os saberes, entre as distintas disciplinas e áreas de conhecimento, ainda que elas se caracterizem, indiscutivelmente, por linguagens próprias, regidas por códigos de expressão diferenciais, que pouco se aproximam das atividades da medicina científica. No entanto, cada vez mais as linguagens seculares da medicina tradicional vão sendo incorporadas pelo setor saúde.

$\mathrm{Na}$ realidade, não se trata aqui de discutir de que modo a interdisciplinaridade e as ações intersetoriais atuam como fatores de mudança da cultura do trabalho na saúde. No entanto, mesmo sem essa intenção específica, o simples fato de trabalhar com as Práticas acaba levando à promoção de ações intersetoriais e interdisciplinares. Pois as Práticas vão muito além das disciplinas específicas. Atualmente, na Secretaria Municipal da Saúde de São Paulo há grande número de voluntários, muitos deles sem qualquer formação ou especialização em saúde, que conduzem grupos de práticas corporais e meditativas junto às unidades de 
saúde. São pessoas comuns da população que trabalham, inclusive, na construção de canteiros de plantas medicinais, resgatando seu uso popular e tradicional no combate a inúmeros problemas de saúde, especialmente aqueles ligados à assistência primária em saúde. Há hoje na SMS-SP mais de 150 hortas de plantas medicinais, muitas delas construídas e mantidas por voluntários.

Além disso, a SMS vem estreitando suas relações com outras secretarias municipais, como as secretarias da Educação, Cultura, Esportes, do Verde e Meio Ambiente e das Subprefeituras. Um dos canais mais favoráveis a esse diálogo intersecretarial são as Práticas. Nos últimos anos, mais de duas dezenas de cursos de fitoterapia e plantas medicinais foram realizados em estreita parceria entre as secretarias da Saúde e Verde e Meio Ambiente. Cerca de 1.500 pessoas participaram, incluindo desde agentes comunitários de saúde e proteção ambiental até profissionais mais graduados, como médicos, enfermeiros, fisioterapeutas, psicólogos e farmacêuticos. Processo semelhante vem ocorrendo em outras secretarias municipais. O exemplo mais recente é o Programa Saúde na Escola (PSE), no qual as secretarias da Educação e da Saúde atuam em estreita parceria. Dentre as diversas atividades desenvolvidas na comunidade escolar destacam-se os canteiros com as hortaliças e plantas medicinais e as práticas corporais e meditativas.

Na Figura 1 pode-se observar o trabalho que um agente do Programa Ambientes Verdes e Saudáveis (PAVS), ligado à Estratégia de Saúde da Família da SMS-SP, vem desenvolvendo junto aos alunos de uma escola municipal localizada na zona norte da capital.

O Programa Ambientes Verdes e Saudáveis é reconhecido como um dos programas da Secretaria Municipal da Saúde que mais promovem articulações intersetoriais e intersercretariais em busca de proteção do meio ambiente e da vida. Seu campo de atuação abrange, especialmente, a poluição da água e do ar, a erosão da terra, as agressões sistemáticas à biodiversidade e a degradação da vida social.

Desenvolvido no período entre 2005 e 2008 por iniciativa da Secretaria Municipal do Verde e do Meio Ambiente, em articulação com o Programa das Nações Unidas para o Meio Ambiente, a partir daí o Programa vem enfrentando uma série de problemas decorrentes da situação de degradação do meio e da vida. A ideia básica do programa foi implementar ações intersetoriais para a proteção ambiental, que pudessem, em curto prazo, ter reflexos positivos sobre a saúde da população. Três secretarias municipais comprometeram-se a desenvolver essas ações de forma integrada: a Secretaria da Saúde, a Secretaria do Verde e Meio Ambiente e a Secretaria Municipal de Assistência e Desenvolvimento Social. Foi apenas no final de 2008 que o Programa foi incorporado à Secretaria Municipal da Saúde, sendo incluído na Estratégia da Saúde da Família.

Para atingir os diversos objetivos a que se propõe, o Programa desenvolve centenas de projetos junto às Unidades Básicas de Saúde, em consonância com os principais problemas dos territórios locais, agrupados em sete eixos de inter- 
venção: biodiversidade e arborização; água, ar e solo; gerenciamento de resíduos sólidos; agenda ambiental na administração pública; horta e alimentação saudável; revitalização de espaços públicos; cultura e comunicação.

É importante mencionar alguns exemplos entre os muitos projetos desenvolvidos a partir dos eixos de intervenção mencionados. Um dos casos mais bem sucedidos é, sem dúvida, o Gerenciamento de Resíduos Sólidos, onde as equipes do Programa orientam os profissionais das UBS e a comunidade local sobre os riscos e os agravos decorrentes do descarte inadequado de resíduos. É possível verificar, a partir de acompanhamento realizado pela própria Secretaria, como os Pontos de Entrega Voluntária de materiais recicláveis e as ações de Cata-Bagulho vêm sendo incentivados, assim como os processos de compostagem dos resíduos orgânicos. Outra experiência de interesse são as ações voltadas para o cuidado com a água, o ar e o solo, três recursos naturais cada vez mais sujeitos à degradação. Trabalhando junto às equipes de saúde da Atenção Básica, as equipes do PAVS apoiam programas para despoluição, limpeza e manutenção de rios e córregos, incentivam a utilização de transporte público não motorizado e solidário, além de estimularem o uso racional da água e apoiarem ações de vigilância em saúde ambiental.

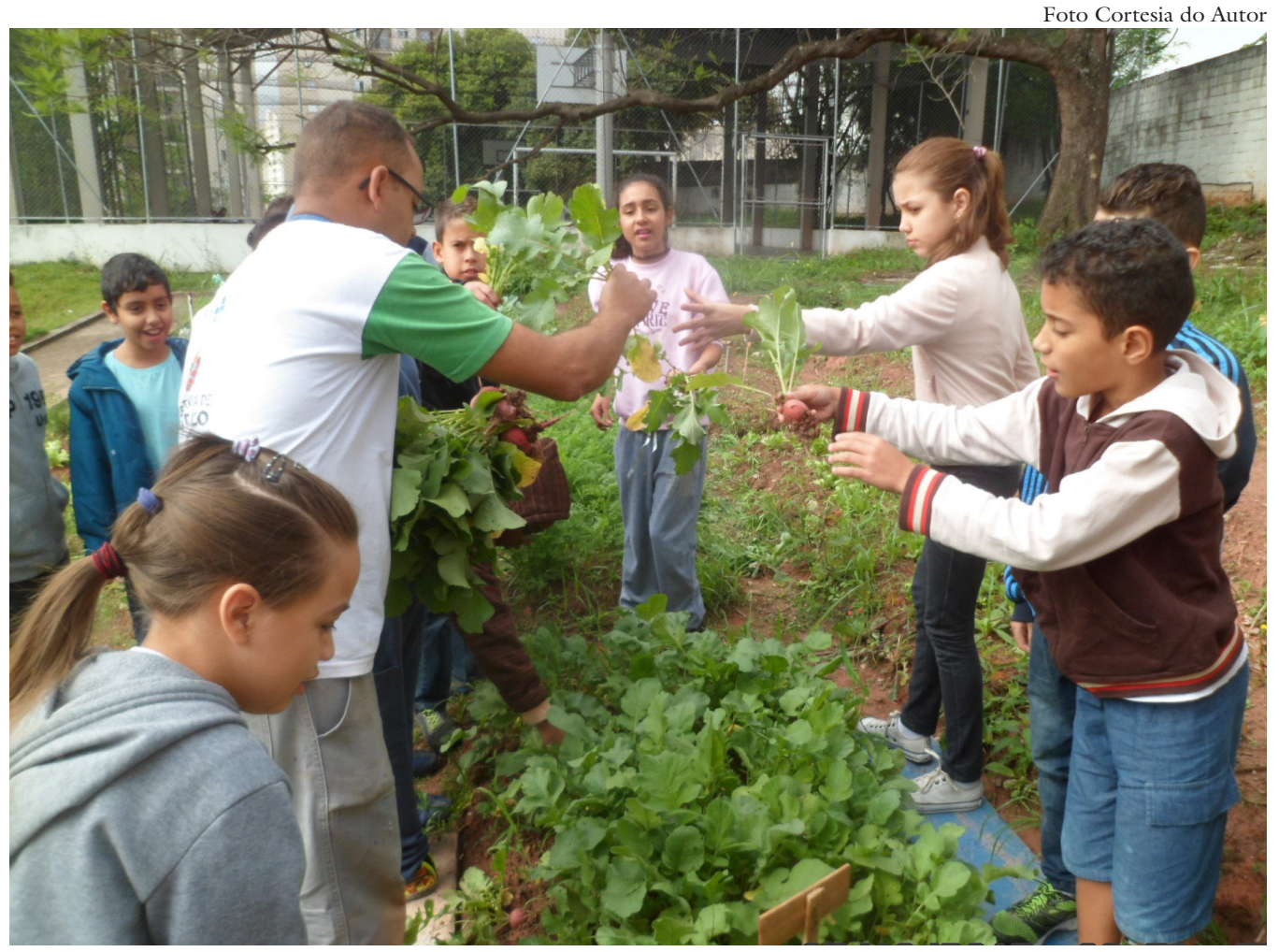

Figura 1 - Agente de saúde do PAVS ensinando o cultivo de hotaliças com alunos de escola municipal da zona norte da capital. 
Os Gráficos 1, 2 e 3 mapeiam a evolução de algumas das práticas corporais desenvolvidas nas unidades de saúde SMS-SP e exercidas pelas distintas categorias profissionais, no período compreendido entre 2004 e 2015.
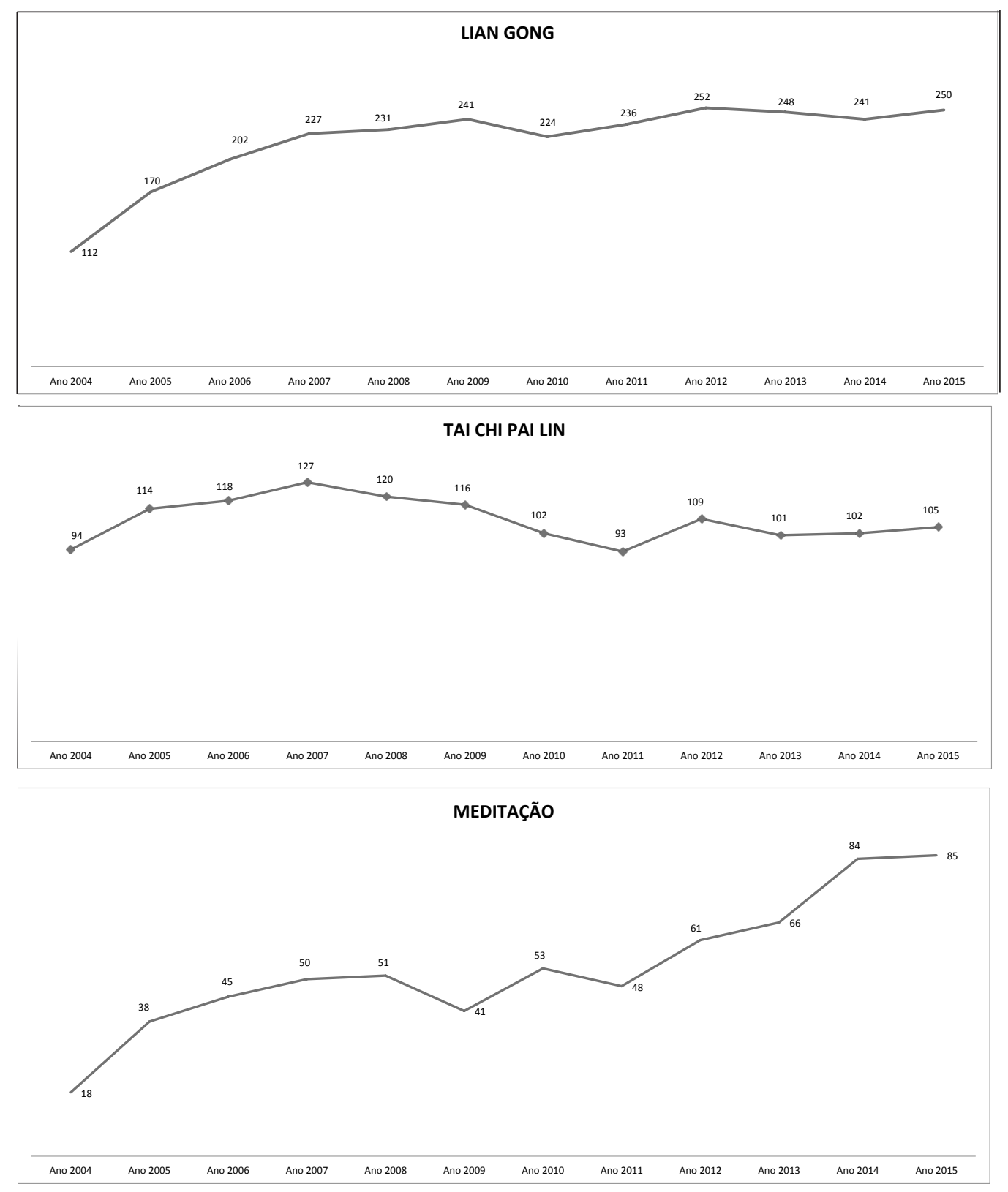

Gráficos 1, 2 e 3 - Número de Unidades de Saúde com algumas das práticas corporais realizadas na SMS. Período de 2004 a 2015. 


\section{Conclusão}

Não é por necessidade de saúde que milhares de pessoas vêm procurando as Práticas como forma de recuperação da saúde. Afinal, temos o que há de mais moderno e avançado na medicina, tanto no SUS como no sistema privado. Não é por falta de procedimentos diagnósticos, médicos, medicamentos ou outros recursos que estamos resgatando o valor das medicinas tradicionais. É por vontade de afirmar uma identidade de cuidado oposta à prática de cuidado feita de forma muitas vezes desumana, que infelizmente prepondera entre nós. As PICS expressam o desejo de mostrar que é possível implementar outras práticas de saúde. O que move as pessoas envolvidas no projeto é, antes de tudo, o impulso de participar ativamente de um processo capaz de mostrar que são possíveis outras formas de aprender, praticar e cuidar da saúde, de si e dos outros.

$\mathrm{O}$ movimento que trabalha pela ampliação das práticas integrativas $\mathrm{e}$ complementares na SMS-SP brota da aspiração de abandonar a passividade, de deixar de ser um sujeito subjugado ao sistema dominante, hegemônico, para inventar novos espaços, pequenos que sejam, para a produção de uma prática alternativa de saúde. Seguindo os imperativos da sensibilidade e da emoção, e não apenas da razão, esse movimento rejeita a feiura generalizada, a pobreza sofrida da grande maioria da população brasileira, e vislumbra uma beleza possível no campo da produção de saúde.

\section{Notas}

l Entende-se por Práticas Integrativas e Complementares em Saúde (PICS) todas as atividades devidamente regulamentadas e inseridas na Política Nacional de Práticas Integrativas e Complementares do Ministério da Saúde (PNPIC/MS), desenvolvidas por meio de ações integradas de caráter interdisciplinar, entre as quais se incluem a Medicina Tradicional Chinesa, a Homeopatia e a Medicina Antroposófica, os Recursos Terapêuticos como a Fitoterapia, as Práticas corporais e meditativas, e o Termalismo-Crenoterapia, além de demais práticas reconhecidas ou que venham a ser reconhecidas pela PNPIC/ MS. Essa política foi aprovada pela Portaria 971 do MS em maio de 2006.

2 "Estrategia de la OMS Sobre Medicina Tradicional 2002-2005", Organización Mundial de la Salud, Ginebra. Esse documento foi atualizado com a publicação de "A estratégia da OMS sobre medicina tradicional 2014-2023", que tem a intenção de auxiliar as autoridades sanitárias a encontrar soluções que propiciem uma visão mais ampla a respeito da melhora da saúde e da autonomia dos pacientes. A estratégia tem dois objetivos principais: prestar apoio aos Estados Membros para que aproveitem a possível contribuição da MTC à saúde, ao bem-estar e à atenção às pessoas, e promover a utilização segura e eficaz da MTC mediante a regulamentação de produtos, práticas e profissionais.

3 O Numepi, Núcleo Interdisciplinar de Pesquisa, Ensino e Assistência nas Areas das Práticas Integrativas e Complementares da Unifesp, há anos vem contribuindo para a consolidação das PICS no Brasil. Dentre seus princípios podem-se destacar a estruturação e o fortalecimento da atenção; o desenvolvimento de qualificação para profissionais; a divulgação e a informação de evidências para profissionais, gestores e usuários; o estímulo 
às ações intersetoriais; o fortalecimento da participação social; o acesso a medicamentos e insumos; o incentivo à pesquisa sobre eficiência, eficácia, efetividade e segurança; o desenvolvimento de acompanhamento e avaliação; a cooperação nacional e internacional; o monitoramento da qualidade. Outra referência a respeito das pesquisas realizadas no Brasil sobre as PICS pode ser encontrada no Caderno Técnico CAEPS - Dant: Capacitação em avaliação da efetividade das ações de promoção da saúde em doenças e agravos não transmissíveis / São Paulo: Prefeitura do Município de São Paulo, 2009. Disponível em: <www.prefeitura.sp.gov.br/.../Caderno Técnico_CAEPS_DANT>. O Caderno Técnico reúne a experiência inédita de vários grupos de trabalho que avaliaram a efetividade de ações de promoção de saúde em doenças e agravos não transmissíveis (Dant) no Município de São Paulo. O projeto teve como objetivo estimular a pesquisa em serviço e capacitar os profissionais da rede de saúde em métodos de pesquisa e avaliação e, com isto, desencadear projetos futuros de monitoramento e avaliação de promoção de saúde em Dant, além de implementar a vigilância em saúde. O pacto inicial, de natureza participativa, permitiu aos profissionais envolvidos escolherem a ação a ser estudada e analisada. Desse modo, houve grande variedade de temas abordados, desde doenças crônicas como hipertensão arterial e diabetes até pesquisas sobre as ações de promoção da saúde e prevenção de doenças trabalhadas pelas medicinas tradicionais e práticas integrativas e complementares em saúde. As investigações demonstram a importância das PICS no âmbito da assistência primária em saúde. As pesquisas em serviço na área de avaliação da efetividade de ações de promoção de saúde e prevenção de doenças foram incluídas também em um projeto de pesquisa em parceria com o Cepedoc (Centro de Estudos, Pesquisa e Documentação Cidades Saudáveis) da Faculdade de Saúde pública da USP e CNPq (Conselho Nacional de Desenvolvimento Científico e Tecnológico) com o objetivo de elaborar um instrumento de avaliação para ações de promoção da saúde. O acesso por via eletrônica pode ser feito por

<http://www.prefeitura.sp.gov.br/cidade/secretarias/saude/vigilancia_em_saude/ doencas_e_agravos/index.php?p=6117>.

4 Desde esse período, o PAVS vem trabalhando de modo integrado em todas as Supervisões Técnicas de Saúde com os seguintes objetivos (Guia PAVS, 2012): fortalecer as ações de promoção à saúde; construir agendas integradas entre saúde e meio ambiente; problematizar, contextualizar e refletir sobre as ações inter setoriais no âmbito de cada território local; propor ações sustentáveis no âmbito local; trabalhar pelo fortalecimento da intersetorialidade e interdisciplinaridade; promover a cultura de paz e não violência; contribuir para a redução de impactos ambientais; contribuir para a efetiva participação da comunidade local; reconhecer a interdependência dos seres da natureza.

\section{Referências}

APEZECHEA, H. Aspectos metodológicos da la Investigación de Servidos de Salud. In: Memorial de Taller de Cocoyoc. Cidade do México: Morelos, 1984.

AYRES, J. R. C. M. Cuidado e reconstrução das práticas de saúde. In: MINAYO, M. C. S.; COIMBRA JÚNIOR, C. E. A. (Org.) Criticas e atuantes: Ciências Sociais e Humanas em Saúde na América Latina (on line). Rio de Janeiro: Ed. Fiocruz, 2005.

GLEISER, M. A dança do universo. São Paulo: Cia. das Letras, 1997.

GUIA PAVS. Secretaria Municipal da Saúde. Coordenação da Atenção Básica. Programa Ambientes Verdes e Saudáveis. São Paulo: SMS, 2012. 
LAO TSE. Tao Te Ching: Livro do Caminho e da Virtude. Sociedade Taoista do Brasil. s. d. Disponível em: <http://www.taoismo.org.br>.

LUZ, T. M. Racionalidades médicas e terapêuticas alternativas. In: Série - Estudos de Saúde Coletiva, número 062. Universidade do Rio de Janeiro, UERJ, outubro de 1993. MINAYO, M. C. S. Os muitos Brasis - saúde e população na década de 80. São Paulo: Hucitec; Rio de Janeiro: Abrasco, 1995.

PADILlA CORRAL, J. L. Fundamentos da Medicina Tradicional Oriental. São Paulo: Roca, 2006.

PAUL, P. Saúde e transdisciplinaridade. São Paulo: Edusp, 2013.

RESUMO - As práticas integrativas e complementares em saúde paulatinamente se tornaram uma realidade na rede de atenção à saúde pública em todo o país. O seu uso no Sistema Único de Saúde merece reflexão, especialmente quando se investiga o sentido de sua adoção no Brasil, uma sociedade complexa que tem incorporado recursos tecnológicos cada vez mais sofisticados e dispendiosos. Esse avanço pode ser entendido como expressão de um movimento que se identifica com novos modos de aprender e praticar a saúde, uma vez que as práticas integrativas se caracterizam pela interdisciplinaridade e por linguagens singulares, próprias, que se contrapõem à visão altamente tecnológica de saúde que impera na sociedade de mercado, dominada por convênios de saúde cujo objetivo precípuo é gerar lucro e fragmentar o tratamento do paciente em especialidades que não dão conta da totalidade do ser humano em busca de remédio para seus males.

PALAVRAS-CHAVE: Práticas integrativas, Medicinas tradicionais, Interdisciplinaridade, Sustentabilidade.

ABSTRACT - Complementary and integrative health practices gradually became a reality in the public health care network across the country. Their use in the National Health System deserves reflection, especially when investigating the effects of their adoption in Brazil, a complex society that has incorporated increasingly sophisticated and expensive technological resources. This advance can be understood as an expression of a movement identified with new ways of learning and practicing health care, since integrative practices are characterized by interdisciplinarity and by specific languages that are opposed to the high-tech vision of health that prevails in the market society, dominated by health plans whose overriding purposes are to generate profit and to fragment the patient's treatment into specialty areas that do not take into account the totality of the human being seeking a remedy for their ills.

KEYWORDS: Integrative practices, Traditional medicines, Interdisciplinary, Sustainability.

Emilio Telesi Júnior é médico sanitarista, doutor em Saúde Pública pela Faculdade de Saúde Pública da USP, atualmente respondendo pela coordenação da Área Técnica das Práticas Integrativas e Complementares em Saúde da Atenção Básica, Secretaria Municipal de Saúde de São Paulo. @ - etelesi@prefeitura.sp.gov.br

Recebido em 22.2.2016 e aceito em 5.3.2016.

I Secretaria Municipal de Saúde de São Paulo, São Paulo, São Paulo, Brasil. 